\title{
Guatemala, Asilo de Escritores Hispanoamericanos
}

A UNQUE, Guatemala no produjo ningún poeta eximio a prin-
cipios del modernismo, atrajo a muchos poetas famosos de entonces o que lo fueron más tarde. Los poetas eligieron a Guatemala o de refugio político, como lo hizo Martí, o a causa de las reformas sociales y políticas, instituidas por Rufino Barrios, como en el caso de Valerio Pujol. Cualquiera que fuese la causa de su viaje, significativo e interesante es el número de literatos eminentes que fueron a vivir en Guatemala.

José Joaquín Palma, el poeta cubano, fué uno de los primeros en visitar Guatemala. Vino durante los primeros años del 70, desterrado de su patria, después de haber visitado los Estados Unidos y Sudamérica. Se quedó hasta su muerte en Guatemala, donde desempeñó muchas tareas periodisticas. En el año de 1891 fué nombrado director de la Biblioteca Nacional. En lo que se refiere a ese país, su labor más importante fué la de profesor de literatura en la Universidad, tomando a su cargo la instrucción de toda una generación de jóvenes. Ira poesía de Palma era tan popular y tan leída que aparecieron muchos imitadores de su estilo. Máximo Soto Hall dice que "hacer versos a lo Palma casi fué una moda". I Escribió Palma muchos versos alabados por Rubén Dario y Marti. Tan guatemalteco se hizo, que compuso el Himno Nacional de Guatemala.

José Martí vino a Guatemala en marzo de 1877 , despidiéndose del país el 27 de julio de 1878. 2 José María Yzaguirri, otro cubano asilado, y Director de la Escuela Central, le nombró profesor de literatura en ese plantel, Luis Rodriguez-Embil nos dice que: 
La escuela recibió al nuevo Profesor tan bien como le recibiera el Presidente de ideas "modernas", y de procedimientos discutibles. primitivos a veces $y$ sangrientos, aunque dirigidos por un evidente anhelo de superación nacional, y de aspecto de mayoral indio. La escuela quedó encantada, desde el primer dia, con el joven Profesor de ojos inolvidables y palabra viva que hería la fantasía al par que iluminaba y nutria la inteligencia con cariño y sin mayor esfuerzo. Los alumnos, de ambos sexos, salian de clases con remolona lentitud. hablando de la lección y del Maestro. 3

La residencia de Martí en Guatemala fué muy agradable. Isidro Méndez óbserva que:

Las voces interiores, como la sibila a los antiguos, le habian augurado bien. En Guatemala, efectivamente, vivió los días más apacibleş de su vida... 4

La narración de Martí, escrita en estilo acelerado y cálido, nos da testimonio de sus vivas impresiones del hogat prohijado. Para la generación nueva, Martí y Palma fueron figuras heroicas, poseedoras de un estilo nuevo en la literatura. Martí fué vicepresidente de El Porvenir, revista literaria muy distinguida, y el fundador de otra, La Revista Guatemalteca, en 1877. David Vela, crítico guatemalteco contemporáneo, ha escrito un relato detallado 5 de Martí en Guatemala, pero su obra desgraciadamente todavía está en manuscrito esperando la imprenta.

El gran peruano, escritor de tradiciones, Ricardo Palma, también hizo una visita a Guatemala, quizá durante el año 1890. No se ha logrado verificar la fecha exacta de su viaje. Del relato de Rubén Dario con relación a su encuentro con Palma en 1888, sabemos que el peruano conocía íntimamente las obras literarias de Pepe Batres y de Domingo Estrada. Las poesías de Palma aparecieron muy a menudo en los periódicos guatemaltecos desde principios del año 70.

Entre los más distinguidos viajeros que visitaron a Guatemala se cuenta a Rubén Dario, quien llegó por primera vez en 1888 , regresando en 1890 para editar un periódico, El Correo de la Tarde, auspiciado por el Presidente Barillas, a quien persuadió Palma para que le prestase ayuda a Dario. Este periódico no duró mucho tiempo, siendo publicado desde el 8 de diciembre de 1890 hasta el 5 de 
junio de 1891, fecha en que le retiró su protección el Presidente. Durante su corta vida el periódico de Darío gozó de gran circulación, debido principalmente a la reputación del fundador; pero contenía el periódico muchos artículos de veras estimulantes. José Luis Vega B. dice:

Las páginas de aquel periódico eran un cû́mulo de herejías poéticas para los fieles a los preceptos de Hermosilla y leales a la metafísica de Balmes. 6

Darío publicó en este periódico algunos cuentos que se incluyeron más tarde en sus obras.

La permanencia de Dario en Guatemala no careció de ventajas para la literatura de ese país. Los jóvenes que trabajaron con él fueron muy influidos por las ideas críticas del gran poeta. Escritores como Enrique Gómez Carrillo, Máximo Soto Hall, Rafael Spinola y Carlos Meany trabajaron con Darío en El Correo de la Tarde y recibieron de él valiosos consejos. Domingo Estrada se habia interesado en los poetas franceses mucho más antes y había escrito varios artículos sobre la poesía francesa; pero bajo el estímulo de Dario, el guatemaiteco escribió diversas obras criticas que se imprimieron en El Correo de la Tarde.

Guatemala se interesó muchisimo en Darío y sus escritos; tanto es asi que Lainfesta, también buen poeta, publicó la segunda edición de $A z u l . .$. en 1890 , costeada por el gobierno. Esta edición incluyó unos poemas en francés y unos cuentos en prosa que no se publicaron en la primera edición de 1888.

Relátanse muchos cuentos de Dario en Guatemala; era notorio su amor propio; Gómez Carrillo nos cuenta que trabajó con Dario sin recibir sueldo, y que cuando el presidente Barillas dió al guatemalteco un estipendio para continuar sus estudios en París, Darío le dió un abrigo elegante y muy a la moda en pago del salario atrasado, aunque el nicaragüense, deseando tildarse de gran señor, declaró a todo el mundo que era un regalo. El guatemalteco, un poco desdeñoso de la arrogancia de Darío, relata cómo se escogió para el periódico el nombre El Correo de la Tarde. Festejándose en una cantina un día el poeta y sus compañeros, trataron de escoger un título que llamara la atención del público. El mismo nicaragüense sugirió el nombre, continúa Gómez Carrillo, y 
José echóse a reir. . El otro compañeto calló. Y Rubén, acostumbrado a creer que todo lo que él imaginaba era perfecto, tomó nuestras ironías por marcas de aprobación y decretó que ya no había necesidad de buscar más, que El Correo de la Tarde resultaba inmejorable. 7

Es de notar que Darío pasó sus últimos días en Guatemala, habiéndosele traído allí mediante los esfuerzos de Soto Hall para escribir un elogio a Cabrera, que nunca comenzó porque su gran mentalidađ̃ ya se había desmoronado por completo. Arévalo Martínez ha escrito una serie de bosquejos de las postrimerías del nicaragüense en el Boletín de la Biblioteca Nacional.

Se radicó también por algún tiempo en Guatemala el gran poeta peruano José Santos Chocano. Vino por primera vez en 1901, en una misión del gobierno del Perú, a discutir el arbitraje como medio para arreglar disputas entre las naciones hispánicas del nuevo mundo. Se imprimió su discurso con el título de "El arbitraje obligatorio en América - Conferencia dada en Guatemala por José Santos Chocano, de la Liga de Propaganda y del Derecho en América y de la Asociación Americana de la Paz. Julio de 1901". Este título altisonante hace mucha gracia cuando se consideran más tarde las relaciones de Chocano con la política de Guatemala.

La popularidad de Chocano fué instantánea y permanente. Su vigor y entusiasmo se contagiaron a todo el mundo. Se le delineó de esta manera al visitar Guatemala por primera vez:

Vimos al personaje extraño, vestido con excesiva elegancia; un levitón color de tabaco, con terciopelo en el cuello, pantalones de la misma tela del levitón, el cuello de la camisa alto y tieso que inmovilizaba la cabeza del dueño, una corbata ancha de lazo, unos zapatos de color y un enorme crisantemo en la solapa đel levitón. . . unos bigotes agresivos como dos tenazas de crustáceo y una mirada llena de altivez. Se le tomara por un rastacuero, si no hubieta en aquella mirada algo de distinción, a través de la soberbia con que movia los ojos. 8

Pero como polemista Chocano se encontró la horma de su zapato en Enrique Martinez Sobral, tan buen novelista como abogado perspicaz. Su lógica fría era “...capaz de apagar los ardores im- 
presos por las frases del enorme poeta". 9 Este debate se ha hecho histórico en Guatemala.

Chocano vivió a intervalos en el país, por unos veinte años; se casó con una hija de Batres Játuregui y su hija, Alma América, nació de esa unión.

La influencia de Chocano sobre los escritores jóvenes fué tremenda. Poetas como Arévalo Martínez, Carlos Rodríguez Cerna y Carlos Wyld Ospina fueron instruídos por el maestro peruano en el arte de componer versos y siguieron su estilo mucho tiempo después. Como Darío, Chocano se ha hecho legendario en Guatemala. Hasta el presente nadie ha escrito un libro de su estancia alli, ni se ha sacado a la luz del día su carrera política. Sin embargo, la mayoría de la gente dice que Chocano era el poder que gobernó a Cabrera en La Palma, donde - se lo dijo a Wyld Ospina - "Cabrera y él estaban presos en un círculo dantesco". 10

Circulan muchos cuentos acerca de los proyectos fantásticos en que se ocupó Chocano. Uno es el del establecimiento de una casa editorial con el propósito de imprimir libros hispanoamericanos. Có mo se figuró hacerse rico imprimiendo libros que no se pueden vender en países cuya lengua es común a todos, nadie puede decirlo. Pero el proyecto que seguramente le hubiera hecho rico era el monopolio del maíz y del frijol, monopolio que le prometió Cabrera pero que, afortunadamente para los dos, nunca se realizó.

Para nación $\tan$ pequeña y $\tan$ escasamente conocida, puede Guatemala jactarse de haber protegido tanto los ideales literarios como a los escritores. Dos de los poetas más destacados de Hispanoamérica le deben ayuda financiera durante tiempos críticos de su vida, y debieron ellos hallar simpático su ambiente intelectual, pues de lo contrario no se hubieran quedado alli. Martí alaba muchísimo a los escritores guatemaltecos, y Darío y Chocano señalaron a Carlos Wyld Ospina y a Arévalo Martínez como poetas que el futuro aclamaría como sucesores de ellos mismos. Lo curioso es que el mundo académico no ha hecho mucho caso del papel que Guatemala ha desempeñado en las letras hispanoamericanas. 


\section{NOTAS}

1 Máximo Soto Hall, Revelaciones intimas de Rubén Dario, p. 16.

2. M. Isidro Méndez, Marti, p. 95.

3 Luis Rodriguez-Embil, José Marti, el santo de América, La Habana, 1941, p. 83.

4 M. Isidro Méndez, Marti, p. 98.

5 Soto Hall ba publicado otro libro sobre Marti en Guatemala, en agosto de 1941. No nos ha sido posible obtener un ejemplar.

6 José Luis Vega B., Rufino Bartios y su obra, p. 38.

7 Enrique Gómez Carrillo, El despertar del alma, vol, X, Obras Completas, p. 222.

8 Tomado de un recorte petiodístico de Guatemala, sin fecha, facilitado por Arturo Taracena Flores.

9 Idem.

10 Carlos Wyld Ospina, El autócrata, p. 220. 